\title{
TITLE:
}

\section{$<$ Note $>$ Chimpanzee Attitude toward a Seriously Weakened Adolescent Female at Mahale}

\section{$\operatorname{AUTHOR}(S)$ :}

Shimada, Masaki; Matumula, Mosi

\section{CITATION:}

Shimada, Masaki ... [et al]. <Note> Chimpanzee Attitude toward a

Seriously Weakened Adolescent Female at Mahale. Pan Africa News 2004, 11(1): 6-8

ISSUE DATE:

2004-06

URL:

http://hdl.handle.net/2433/143437

RIGHT:

Copyright (C) Pan Africa News. 


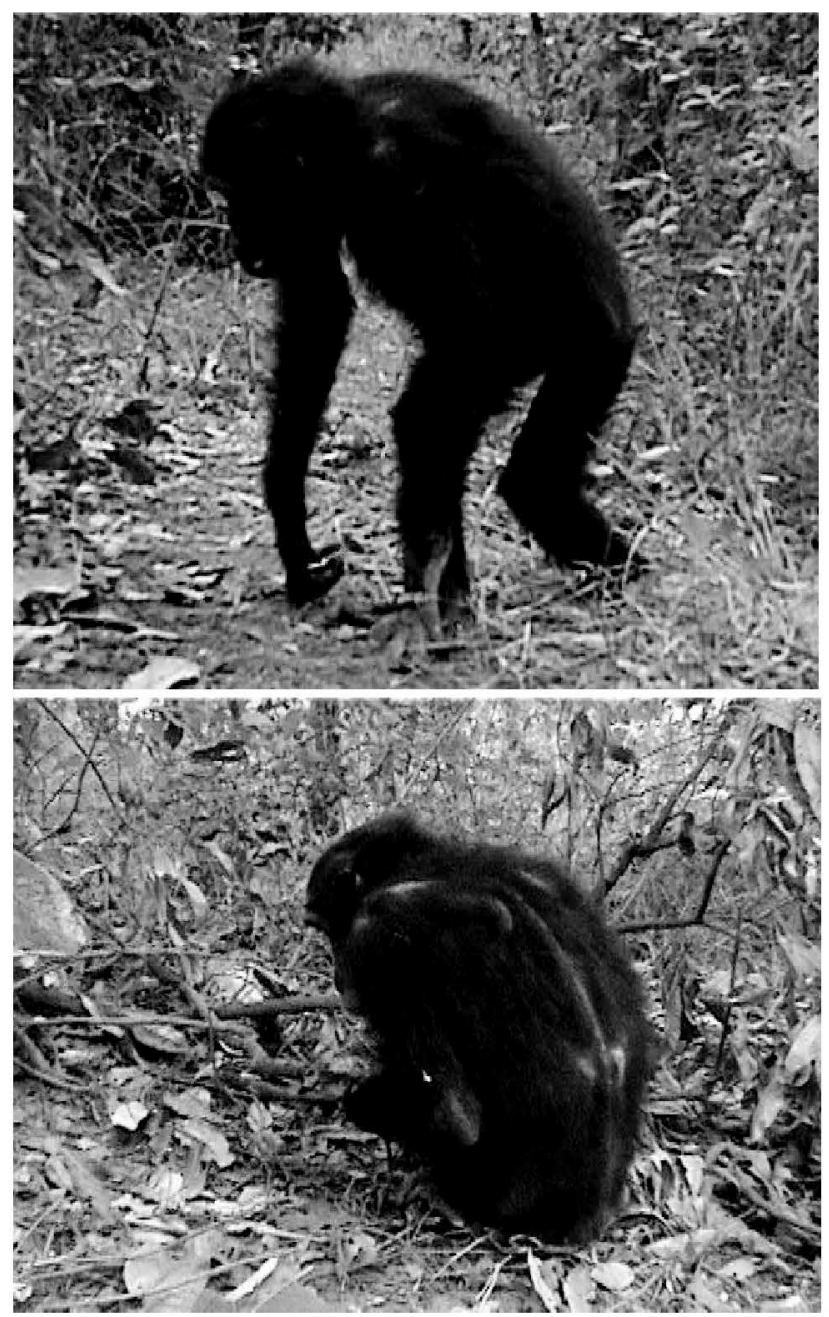

Figure 1. Ai, walking slowly (upper photo) and Ai's skinny back and limb (lower photo)

group, became weak gradually and disappeared after 3 years.

de Waal (1) and Goodall (2) reported that some chimpanzees become "anxious" about seriously wounded or disabled individuals, and that the other chimpanzees were "fearful" of or "antagonistic" to them.

In this report, we focus on the change in Ai's health condition and whether the types of interactions reported by previous authors were also observed in Ai's case. We discuss the unique features of this interaction, including observations of Ai just before she became lost, based on data sampled by focal animal sampling and ad lib sampling methods.

\section{Masaki Shimada, Kyoto University Mosi Matumula, Mahale Mts. Chimpanzee Research Project}

$\mathrm{Ai}$, a young adult female chimpanzee of the $\mathrm{M}$

\section{Observations}

1. Changing Condition of $\mathrm{Ai}$ and Her Disappearance

We interviewed several researchers and field 
assistants who had studied Ai's physical trouble in Mahale. To summarize their reports, Ai began showing inconvenient and awkward movement in both of her legs in June or July 1999, when she was 11 years old (Ai was born in September 1988), without any external wound. Ai was able to walk and climb up trees, even though it seemed hard to move both of her legs. The rest of her body above the waist apparently had no trouble. These symptoms showed no change before her disappearance, and the reason for her trouble was unknown.

Ai had been gradually weakening over the course of three years. However, until February 2002, Ai was observed to slowly follow the other chimpanzees forming large cohesive parties and sometimes even to play with the others.

After she was missing for four months, we encountered Ai again on May 26, 2002 and found that she frequently stumbled over the ground and could barely walk (Figure 1). The last observation of Ai was on June 29, 2002, and she seemed so sick that she could hardly walk straight.

\section{Observation of Interaction Involving Ai}

We observed Ai for 12 days from May 26 to June 29, 2002. We followed her as a target individual for 6 days, totally 25.1 hours. Ai stayed in the open forest in the southern part of the range of the $\mathrm{M}$ group for $66.8 \%$ of the observation time. We observed 11 events in which Ai and the other individuals associated with each other. Mean party size, including $\mathrm{Ai}$, was $1.8(\mathrm{SD}=1.1)$.
In the 11 associating events, we observed no individuals behaving "fearfully" to Ai (grin, full embrace, or avoid), while some adult female(s) behaved "antagonistically" (attack) in three events. Ai had her old mother and senior brother, and they and other individuals behaved "anxiously" to Ai (care, pat or share food), except for the cases where females showed aggression toward Ai.

In two out of the three events when female(s) attacked Ai, non-kin individuals intervened against these attacks, consequently stopping them (Table 1).

\section{Discussion}

The females of the M group normally show the first swelling of their sexual skin around 10.7-years-old and then emigrate to the other unit groups around 11.3-years-old (3). It is supposed that Ai was too sick to sexually mature and to emigrate to the other groups. Although we could not confirm her death or observe her dead body directly, it seems obvious that she did not emigrate to another group but died a few days after her disappearance, probably by starvation or predation by wild animals like leopards. In fact, a skull and some long bones that were likely Ai's were later found.

In June 2002, plenty of fallen fruits of Parinari curatellifolia were found on the ground in limited parts of the southern open forest. Ai was staying alone under Parinari trees and crawled within a small area to feed on the fruits on the ground almost everyday, since it seemed

Table 1. The cases adult female(s) attacked Ai and the intervention

\begin{tabular}{|c|c|c|c|c|c|c|}
\hline $\begin{array}{l}\text { Case } \\
\text { No. }\end{array}$ & Date & $\begin{array}{l}\text { Associating } \\
\text { Individuals* }\end{array}$ & Place & Attack & Intervention & $\begin{array}{c}\text { Wound on } \\
\mathrm{Ai}\end{array}$ \\
\hline 1 & 26 May '02 & $\mathrm{Zl}$ & Forest & $\begin{array}{l}\text { After feeding with } \mathrm{Ai} \text { on } \\
\text { the same tree, } \mathrm{Zl} \text { chased } \mathrm{Ai} \\
\text { and hit her on the back }\end{array}$ & no & no \\
\hline 2 & 14 June '02 & $\mathrm{Cy}, \mathrm{Ak}$ & $\begin{array}{c}\text { Open } \\
\text { Forest }\end{array}$ & $\begin{array}{l}\mathrm{Cy} \text { and } \mathrm{Ak} \text { approached } \mathrm{Ai}, \\
\text { then suddenly } \mathrm{Cy} \text { charged } \\
\text { and bit } \mathrm{Ai} \text { on the left foot }\end{array}$ & $\begin{array}{l}\text { Ak charged } \mathrm{Cy} \text {, then } \mathrm{Cy} \\
\text { chased } \mathrm{Ak} \text { and } \mathrm{Ak} \\
\text { escaped screaming }\end{array}$ & $\begin{array}{l}\text { Lacerated } \\
\text { wound on } \\
\text { left foot }\end{array}$ \\
\hline 3 & 18 June '02 & $\stackrel{* *}{\mathrm{Op}}, \mathrm{Rb}, \mathrm{OR}, \mathrm{Ft}$ & $\begin{array}{c}\text { Open } \\
\text { Forest }\end{array}$ & $\begin{array}{l}\text { After staying with } \mathrm{Op} \text { and } \\
\text { the others for } 40 \text { minutes, } \\
\text { a juvenile bit } \mathrm{Ai} \text {. Rb and } \\
\text { Op charged and slapped } \mathrm{Ai}\end{array}$ & $\begin{array}{l}\text { OR approached and } \\
\text { intruded bipedally } \\
\text { between } \mathrm{Ai} \text { and } \mathrm{Op}-\mathrm{Rb} \text {. } \\
\text { Then OR turned his } \\
\text { back to Op-Rb. Op and } \\
\text { Rb stopped attacking Ai }\end{array}$ & $\begin{array}{l}\text { Lacerated } \\
\text { wound on } \\
\text { left hand }\end{array}$ \\
\hline
\end{tabular}

\footnotetext{
* Females have the second letter writen small, while males capital. Names of infants and juveniles are omitted.
} $\because *$ Op, Rb and OR are kin. 
already difficult for Ai to walk to another food tree or to climb up trees to feed.

Compared with the cases reported by previous authors $(1,2)$, the unique features of Ai's case are, first, that females rather than males bullied $\mathrm{Ai}$ just before she was lost, and, second, that non-kin individuals rather than kin intervened against these attacks by females.

It is known that among female chimpanzees the frequency of aggressive interaction is very low and that bullying seldom occurs $(2,4)$. Nevertheless, attacks against Ai happened at least three times over 12 days, and Ai suffered wounds twice by the attackers. Because Ai did not suffer attacks by females when she was comparatively healthier, some females became "antagonistic" to Ai only after she had become seriously weakened.

Two cases of intervention by non-kin individuals were newly observed. They took high risks to support $\mathrm{Ai}$ : In case 2, Cy's rank was higher than Ak's, and in case 3, OR intruded alone against two attackers, Op (OR's mother) and $\mathrm{Rb}$ (OR's sister). OR intervened "neutrally" in a non-aggressive way by turning his back to the attackers (Table 1). As a result, he succeeded in stopping the attack without suffering any attack by his mother or sister. This may be a good example of chimpanzees' high cognitive capacity for solving social problems.

The field study was financially supported by a MEXT Grant-in-Aid for Scientific Research (Basic Research A1,\#12375003 to T. Nishida).

\section{References}

(1) de Waal FBM 1996. Good Natured: The Origins of Right and Wrong in Humans and Other Animals. Harvard University Press, Cambridge, Mass.

(2) Goodall J 1989. The Chimpanzees of Gombe: Patterns of Behavior: Harvard University Press, Cambridge, Mass.

(3) Nishida T, Uehara S and Kawanaka K (eds.) 2002. The Mahale Chimpanzees: Thirty-seven Years of $<$ Panthropology>. Kyoto University Press, Tokyo, in Japanese.

(4) Nishida $\mathrm{T}$ 1989. Social interactions between resident and immigrant female chimpanzees. In: Understanding Chimpanzees, Heltne PG and Marquardt LA (eds.), Harvard University Press, Cambridge, Mass. 